\title{
Regularization proximal point algorithm for finding a common fixed point of a finite family of nonexpansive mappings in Banach spaces
}

Jong Kyu Kim ${ }^{1 *}$ and Truong Minh Tuyen ${ }^{2}$

\author{
* Correspondence: \\ jongkyuk@kyungnam.ac.kr \\ ${ }^{1}$ Department of Mathematics \\ Education, Kyungnam University, \\ Masan, Kyungnam, 631-701, Korea \\ Full list of author information is \\ available at the end of the article
}

\author{
Abstract \\ We study the strong convergence of a regularization proximal point algorithm for \\ finding a common fixed point of a finite family of nonexpansive mappings in a \\ uniformly convex and uniformly smooth Banach space. \\ 2010 Mathematics Subject Classification: 47H09; 47J25; 47J30. \\ Keywords: accretive operators, uniformly smooth and uniformly convex, Banach \\ space, sunny nonexpansive retraction, weak sequential continuous, mapping, \\ regularization
}

\section{Introduction}

Let $E$ be a Banach space with its dual space $E^{*}$. For the sake of simplicity, the norms of $E$ and $E^{*}$ are denoted by the symbol $\|\cdot\|$. We write $\left\langle x, x^{*}\right\rangle$ instead of $x^{*}(x)$ for $x^{*} \in E^{*}$ and $x \in E$. We denote as $\rightarrow$ and $\rightarrow$, the weak convergence and strong convergence, respectively. A Banach space $E$ is reflexive if $E=E^{* *}$.

The problem of finding a fixed point of a nonexpansive mapping is equivalent to the problem of finding a zero of the following operator equation:

$$
0 \in A(x)
$$

involving the accretive mapping $A$.

One popular method of solving equation $0 \in A(x)$ is the proximal point algorithm of Rockafellar [1] which is recognized as a powerful and successful algorithm for finding a zero of monotone operators. Starting from any initial guess $x_{0} \in H$, this proximal point algorithm generates a sequence $\left\{x_{n}\right\}$ given by

$$
x_{n+1}=J_{c_{n}}^{A}\left(x_{n}+e_{n}\right),
$$

where $J_{r}^{A}=(I+r A)^{-1}, \forall r>0$ is the resolvent of $A$ in a Hilbert space $H$. Rockafellar [1] proved the weak convergence of the algorithm (1.2) provided that the regularization sequence $\left\{c_{n}\right\}$ remains bounded away from zero, and that the error sequence $\left\{e_{n}\right\}$ satisfies the condition $\sum_{n=0}^{\infty}\left\|e_{n}\right\|<\infty$. However, Güler's example [2] shows that proximal point algorithm (1.2) has only weak convergence in an infinite-dimensional Hilbert space. Recently, several authors proposed modifications of Rockafellar's proximal point algorithm (1.2) for the strong convergence. For example, Solodov and Svaiter [3] and

(c) 2011 Kim and Tuyen; licensee Springer. This is an Open Access article distributed under the terms of the Creative Commons Attribution License (http://creativecommons.org/licenses/by/2.0), which permits unrestricted use, distribution, and reproduction in any medium, provided the original work is properly cited. 
Kamimura and Takahashi [4] studied a modified proximal point algorithm by an additional projection at each step of iteration. Lehdili and Moudafi [5] obtained the convergence of the sequence $\left\{x_{n}\right\}$ generated by the algorithm:

$$
x_{n+1}=J_{c_{n}}^{A_{n}}\left(x_{n}\right),
$$

where $A_{n}=\mu_{n} I+A$ is viewed as a Tikhonov regularization of $A$. When $A$ is maximal monotone in a Hilbert space $H, \mathrm{Xu}$ [6], Song and Yang [7] used the technique of nonexpansive mappings to get convergence theorems for $\left\{x_{n}\right\}$ defined by the perturbed version of the algorithm (1.3):

$$
x_{n+1}=J_{r_{n}}^{A}\left(t_{n} u+\left(1-t_{n}\right) x_{n}\right) .
$$

The equation (1.4) can be written in the following equivalent form:

$$
r_{n} A\left(x_{n+1}\right)+x_{n+1} \ni t_{n} u+\left(1-t_{n}\right) x_{n} .
$$

In this article, we study a regularization proximal point algorithm to solve the problem of finding a common fixed point of a finite family of nonexpansive self-mappings in a uniformly convex and uniformly smooth Banach space $E$. Moreover, we give some analogue regularization methods for the more general problems, such as: problem of finding a common fixed point of a finite family of nonexpansive mappings $T_{i}, i=1,2$, ..., $N$, where $T_{i}$ is self-mapping or nonself-mapping on a closed convex subset of $E$.

\section{Preliminaries}

Definition 2.1. A Banach space $E$ is said to be uniformly convex, if for any $\varepsilon \in(0,2]$ the inequalities $\|x\| \leq 1,\|y\| \leq 1,\|x-y\| \geq \varepsilon$ imply that there exists a $\delta=\delta(\varepsilon) \geq 0$ such that

$$
\frac{\|x+y\|}{2} \leq 1-\delta
$$

The function

$$
\delta_{E}(\varepsilon)=\inf \left\{1-2^{-1}\|x+y\|:\|x\|=\|y\|=1,\|x-y\|=\varepsilon\right\}
$$

is called the modulus of convexity of the space $E$. The function $\delta_{E}(\varepsilon)$ defined on the interval $[0,2]$ is continuous, increasing and $\delta_{E}(0)=0$. The space $E$ is uniformly convex if and only if $\delta_{E}(\varepsilon)>0, \forall \varepsilon \in(0,2]$.

The function

$$
\rho_{E}(\tau)=\sup \left\{2^{-1}(\|x+y\|+\|x-y\|)-1:\|x\|=1,\|y\|=\tau\right\},
$$

is called the modulus of smoothness of the space $E$. The function $\rho_{E}(\tau)$ defined on the interval $[0,+\infty)$ is convex, continuous, increasing and $\rho_{E}(0)=0$.

Definition 2.2. A Banach space $E$ is said to be uniformly smooth, if

$$
\lim _{\tau \rightarrow 0} \frac{\rho_{E}(\tau)}{\tau}=0 .
$$

It is well known that every uniformly convex and uniformly smooth Banach space is reflexive. In what follows, we denote

$$
h_{E}(\tau)=\frac{\rho_{E}(\tau)}{\tau} \text {. }
$$


The function $h_{E}(\tau)$ is nondecreasing. In addition, it is not difficult to show that the estimate

$$
h_{E}(K \tau) \leq L K h_{E}(\tau), \quad \forall K>1, \quad \tau>0,
$$

is valid, where $L$ is the Figiel's constant [8-10], $1<L<1$.7. Indeed, we know that the inequality holds ([8])

$$
\frac{\rho_{E}(\eta)}{\eta^{2}} \leq L \frac{\rho_{E}(\xi)}{\xi^{2}}, \quad \forall \eta \geq \xi>0 .
$$

It implies that

$$
\xi h_{E}(\eta) \leq L \eta h_{E}(\xi), \quad \forall \eta \geq \xi>0 .
$$

Taking in (2.7) $\eta=C \tau$ and $\xi=\tau$, we obtain the inequality:

$$
\tau h_{E}(C \tau) \leq L C \tau h_{E}(\tau),
$$

which implies that (2.5) holds. Similarly, we have

$$
\rho_{E}(C \tau) \leq L C^{2} \rho_{E}(\tau), \quad \forall C>1, \quad \tau>0 .
$$

Definition 2.3. A mapping $j$ from $E$ onto $E^{*}$ satisfying the condition

$$
j(x)=\left\{f \in E^{*}:\langle x, f\rangle=\|x\|^{2} \text { and }\|f\|=\|x\|\right\}
$$

is called the normalized duality mapping of $E$.

We know that

$$
j(x)=2^{-1} \operatorname{grad}\|x\|^{2} .
$$

in a smooth Banach space, and the normalized duality mapping $J$ is the identity operator $I$ in a Hilbert space.

Definition 2.4. An operator $A: D(A) \subseteq E \rightarrow E$ is called accretive, if for all $x, y \in D$ $(A)$, there exists $j(x-y) \in J(x-y)$ such that

$$
\langle A(x)-A(y), j(x-y)\rangle \geq 0 .
$$

Definition 2.5. An operator $A: E \rightarrow E$ is called $m$-accretive if it is an accretive operator and the range $R(\lambda A+I)=E$ for all $\lambda>0$, where $I$ is the identity of $E$.

If $A$ is an $m$-accretive operator then it is a demiclosed operator, i.e., if the sequence $\left\{x_{n}\right\} \subset D(A)$ satisfies $x_{n} \rightarrow x$ and $A\left(x_{n}\right) \rightarrow f$, then $A(x)=f[10,11]$.

Definition 2.6. A mapping $T: C \rightarrow E$ is said to be nonexpansive on a closed convex subset $C$ of Banach space $E$ if

$$
\|T x-T y\| \leq\|x-y\|, \quad \forall x, y \in C .
$$

If $T: C \rightarrow E$ is a nonexpansive then $I-T$ is an accretive operator. In this case, if the subset $C$ coincides $E$ then $I-T$ is an $m$-accretive operator.

Definition 2.7. Let $G$ be a nonempty closed convex subset of $E$. A mapping $Q_{G}: E \rightarrow$ $G$ is said to be

(i) a retraction onto $G$ if $Q_{G}^{2}=Q_{G}$; 
(ii) a nonexpansive retraction if it also satisfies the inequality:

$$
\left\|Q_{G} x-Q_{G} y\right\| \leq\|x-y\|, \quad \forall x, y \in E ;
$$

(iii) a sunny retraction if for all $x \in E$ and for all $t \in[0,+\infty)$

$$
Q_{G}\left(Q_{G} x+t\left(x-Q_{G} x\right)\right)=Q_{G} x .
$$

A closed convex subset $C$ of $E$ is said to be a nonexpansive retract of $E$, if there exists a nonexpansive retraction from $E$ onto $C$, and it is said to be a sunny nonexpansive retract of $E$, if there exists a sunny nonexpansive retraction from $E$ onto $C$.

Proposition 2.8. [9] Let $G$ be a nonempty closed convex subset of $E$. A mapping $Q_{G}$ : $E \rightarrow G$ is a sunny nonexpansive retraction if and only if

$$
\left\langle x-Q_{G} x, J\left(\xi-Q_{G} x\right)\right\rangle \leq 0, \quad \forall x \in E, \quad \forall \xi \in G .
$$

Reich [12] showed that if $E$ is uniformly smooth and $D$ is the fixed point set of a nonexpansive mapping from $C$ into itself, then there is a sunny nonexpansive retraction from $C$ onto $D$, and it can be constructed as follows.

Lemma 2.9. [12] Let $E$ be a uniformly smooth Banach space, and let $T: C \rightarrow C$ be a nonexpansive mapping with a fixed point. For each $u \in C$ and every $t \in(0,1)$, the unique fixed point $x_{t} \in C$ of the contraction $C \ni x \mapsto t u+(1-t)$ Tx converges strongly as $t \rightarrow 0$ to a fixed point of T. Define $Q: C \rightarrow$ Fix $(T)$ by $Q u=\lim _{t \rightarrow 0} x_{t}$. Then, $Q$ is a unique sunny nonexpansive retraction from $C$ onto $F i x(T)$, i.e., $Q$ satisfies the property:

$$
\langle u-Q u, j(z-Q u)\rangle \leq 0, \quad u \in C, \quad z \in \operatorname{Fix}(T) .
$$

Definition 2.10. Let $C_{1}$ and $C_{2}$ be convex subsets of $E$. The quantity

$$
\beta\left(C_{1}, C_{2}\right)=\sup _{u \in C_{1}} \inf _{v \in C_{2}}\|u-v\|\left(=\sup _{u \in C_{1}} d\left(u, C_{2}\right)\right)
$$

is said to be a semideviation of the set $C_{1}$ from the set $C_{2}$. The function

$$
\mathcal{H}\left(C_{1}, C_{2}\right)=\max \left\{\beta\left(C_{1}, C_{2}\right), \beta\left(C_{2}, C_{1}\right)\right\}
$$

is said to be a Hausdorff distance between $C_{1}$ and $C_{2}$.

In this article, we will use the following useful lemma:

Lemma 2.11. [7]If $E$ is a uniformly smooth Banach space, $C_{1}$ and $C_{2}$ are closed convex subsets of $E$ such that the Hausdorff distance $\mathcal{H}\left(C_{1}, C_{2}\right) \leq \delta$, and $Q_{C_{1}}$ and $Q_{C_{2}}$ are the sunny nonexpansive retractions onto the subsets $C_{1}$ and $C_{2}$, respectively, then

$$
\left\|Q_{C_{1}} x-Q_{C_{2}} x\right\|^{2} \leq 16 R(2 r+d) h_{E}\left(\frac{16 L \delta}{R}\right),
$$

where $L$ is Figiel's constant, $r=\|x\|, d=\max \left\{d_{1}, d_{2}\right\}$, and $R=2(2 r+d)+\delta$. Here $d_{i}=$ $\operatorname{dist}\left(\theta, C_{i}\right)=d\left(\theta, C_{i}\right), i=1,2$, and $\theta$ is the origin of the space $E$.

\section{Main results}

We need the following lemmas in the proof of our results:

Lemma 3.1. [9]If $A=I-T$ with a nonexpansive mapping $T$, then for all $x, y \in D(T)$, the domain of $T$

$$
\langle A x-A y, J(x-y)\rangle \geq L^{-1} R^{2} \delta_{E}\left(\frac{\|A x-A y\|}{4 R}\right),
$$


where $\|x\| \leq R,\|y\| \leq R$ and $1<L<1.7$ is Figiel's constant.

Lemma 3.2. [13] Let $\left\{a_{n}\right\}$ be a sequence of nonnegative real numbers satisfying the property:

$$
a_{n+1} \leq\left(1-\lambda_{n}\right) a_{n}+\lambda_{n} \beta_{n}+\sigma_{n}, \quad \forall n \geq 0
$$

where $\left\{\lambda_{n}\right\},\left\{\beta_{n}\right\}$ and $\left\{\sigma_{n}\right\}$ satisfy the following conditions.

(i) $\sum_{n=0}^{\infty} \lambda_{n}=\infty$;

(ii) $\lim \sup _{n \rightarrow \infty} \beta_{n} \leq 0$ or $\sum_{n=0}^{\infty}\left|\lambda_{n} \beta_{n}\right|<\infty$;

(iii) $\sigma_{n} \geq 0 \forall n \geq 0$ and $\sum_{n=0}^{\infty} \sigma_{n}<\infty$.

Then, $\left\{a_{n}\right\}$ converges to zero.

Lemma 3.3. [9]Let $E$ be a uniformly smooth Banach space. Then, for all $x, y \in E$,

$$
\|x+y\|^{2} \leq\|x\|^{2}+2\langle y, J x\rangle+c \rho_{E}(\|y\|),
$$

where $c=48 \max (L,\|x\|,\|y\|)$.

First, we consider the following problem:

Finding an element $x^{*} \in S=\cap_{i=1}^{N} \operatorname{Fix}\left(T_{i}\right)$,

where Fix $\left(T_{i}\right)$ is the set of fixed points of the nonexpansive mapping $T_{i}: E \rightarrow E, i=1$, $2, \ldots, N$.

Theorem 3.4. Suppose that $E$ is a uniformly convex and uniformly smooth Banach space which has a weakly sequentially continuous normalized duality mapping $j$ from $E$ to $E^{*}$. Let $T_{i}: E \rightarrow E, i=1,2, \ldots, N$ be nonexpansive mappings with $S=\cap_{i=1}^{N} \operatorname{Fix}\left(T_{i}\right) \neq \emptyset$. If the sequences $\left\{r_{n}\right\} \subset(0,+\infty)$ and $\left\{t_{n}\right\} \subset(0,1)$ satisfy

(i) $\lim _{n \rightarrow \infty} t_{n}=0 ; \sum_{n=0}^{\infty} t_{n}=+\infty$;

(ii) $\lim _{n \rightarrow \infty} r_{n}=+\infty$,

then the sequence $\left\{x_{n}\right\}$ defined by

$$
r_{n} \sum_{i=1}^{N} A_{i}\left(x_{n+1}\right)+x_{n+1}=t_{n} u+\left(1-t_{n}\right) x_{n}, u, x_{0} \in E, \quad n \geq 0
$$

converges strongly to $Q_{s} u$, where $A_{i}=I-T_{i}, i=1,2, \ldots, N$ and $Q_{S}$ is a sunny nonexpansive retraction from $E$ onto $S$.

Proof. First, equation (3.4) defines a unique sequence $\left\{x_{n}\right\} \subset E$, because for each $n$, the element $x_{n+1}$ is a unique fixed point of the contraction mapping $f: E \rightarrow E$ defined by

$$
f(x)=\frac{r_{n}}{N r_{n}+1} \sum_{i=1}^{N} T_{i}(x)+\frac{1}{N r_{n}+1}\left[t_{n} u+\left(1-t_{n}\right) x_{n}\right], \quad x \in E .
$$

For every $x^{*} \in S$, we have

$$
\left\langle r_{n} \sum_{i=1}^{N} A_{i}\left(x_{n+1}\right), j\left(x_{n+1}-x^{*}\right)\right\rangle \geq 0, \quad \forall n \geq 0 .
$$


Therefore,

$$
\left\langle t_{n} u+\left(1-t_{n}\right) x_{n}-x_{n+1}, j\left(x_{n+1}-x^{*}\right)\right\rangle \geq 0, \quad \forall n \geq 0 .
$$

It gives the inequality as follows:

$$
\left\|x_{n+1}-x^{*}\right\|^{2} \leq\left\{t_{n}\left\|u-x^{*}\right\|+\left(1-t_{n}\right)\left\|x_{n}-x^{*}\right\|\right\} \times\left\|x_{n+1}-x^{*}\right\| .
$$

Consequently, we have

$$
\begin{aligned}
\left\|x_{n+1}-x^{*}\right\| & \leq t_{n}\left\|u-x^{*}\right\|+\left(1-t_{n}\right)\left\|x_{n}-x^{*}\right\| \\
& \leq \max \left(\left\|u-x^{*}\right\|,\left\|x_{n}-x^{*}\right\|\right) \\
& \quad \vdots \\
& \leq \max \left(\left\|u-x^{*}\right\|,\left\|x_{0}-x^{*}\right\|\right), \quad \forall n \geq 0 .
\end{aligned}
$$

Therefore, the sequence $\left\{x_{n}\right\}$ is bounded. Every bounded set in a reflexive Banach space is relatively weakly compact. This means that there exists a subsequence $\left\{x_{n_{k}}\right\} \subseteq\left\{x_{n}\right\}$ which converges to a limit $\bar{x} \in E$.

Suppose $\left\|x_{n}\right\| \leq R$ and $\left\|x^{*}\right\| \leq R$ with $R>0$. By Lemma 3.1, we have

$$
\begin{aligned}
\delta_{E}\left(\frac{\left\|A_{i}\left(x_{n+1}\right)\right\|}{4 R}\right) & \leq \frac{L}{R^{2} r_{n}}\left\langle r_{n} A_{i}\left(x_{n+1}\right), j\left(x_{n+1}-x^{*}\right)\right\rangle \\
& \leq \frac{L}{R^{2} r_{n}}\left\langle r_{n} \sum_{k=1}^{N} A_{k}\left(x_{n+1}\right), j\left(x_{n+1}-x^{*}\right)\right\rangle \\
& \leq \frac{L}{R^{2} r_{n}}\left\|t_{n} u+\left(1-t_{n}\right) x_{n}-x_{n+1}\right\| \cdot\left\|x_{n+1}-x^{*}\right\| \\
& \rightarrow 0, \quad n \rightarrow \infty
\end{aligned}
$$

for every $i=1,2, \ldots, N$. Since the modulus of convexity $\delta_{E}$ is continuous and $E$ is a uniformly convex Banach space, $A_{i}\left(x_{n+1}\right) \rightarrow 0, i=1,2, \ldots, N$. It is clear that $\bar{x} \in S$ from the demiclosedness of $A_{i}$. Hence, noting the inequality (2.15), we obtain

$$
\begin{aligned}
\limsup _{n \rightarrow \infty}\left\langle u-Q_{s} u, j\left(x_{n}-Q_{s} u\right)\right\rangle & =\lim _{k \rightarrow \infty}\left\langle u-Q_{s} u, j\left(x_{n_{k}}-Q_{s} u\right)\right\rangle \\
& =\left\langle u-Q_{s} u, j\left(\bar{x}-Q_{s} u\right)\right\rangle \\
& \leq 0 .
\end{aligned}
$$

Next, we have

$$
\begin{aligned}
\left\|x_{n+1}-Q_{S} u\right\|^{2}= & \left\langle-r_{n} \sum_{i=1}^{N} A_{i}\left(x_{n+1}\right)+t_{n} u+\left(1-t_{n}\right) x_{n}-Q_{S} u J\left(x_{n+1}-Q_{s} u\right)\right\rangle \\
= & -\left\langle r_{n} \sum_{i=1}^{N} A_{i}\left(x_{n+1}\right), J\left(x_{n+1}-Q_{s} u\right)\right\rangle \\
& +\left\langle t_{n} u+\left(1-t_{n}\right) x_{n}-Q_{s} u, J\left(x_{n+1}-Q_{s} u\right)\right\rangle \\
\leq \leq & \left\langle t_{n}\left(u-Q_{s} u\right)+\left(1-t_{n}\right)\left(x_{n}-Q_{s} u\right), J\left(x_{n+1}-Q_{s} u\right)\right\rangle \\
\leq & \frac{1}{2}\left\{\left\|t_{n}\left(u-Q_{s} u\right)+\left(1-t_{n}\right)\left(x_{n}-Q_{s} u\right)\right\|^{2}+\left\|x_{n+1}-Q_{s} u\right\|^{2}\right\} .
\end{aligned}
$$

By the Lemma 3.3 and the above inequality, we conclude that

$$
\begin{aligned}
\left\|x_{n+1}-Q_{s} u^{2}\right\| \leq & \left\|t_{n}\left(u-Q_{s} u\right)+\left(1-t_{n}\right)\left(x_{n}-Q_{s} u\right)\right\|^{2} \\
\leq & \left(1-t_{n}\right)^{2}\left\|x_{n}-Q_{s} u\right\|^{2}+2 t_{n}\left(1-t_{n}\right)\left\langle u-Q_{s} u, j\left(x_{n}-Q_{s} u\right)\right\rangle \\
& +c \rho_{E}\left(t_{n}\left\|u-Q_{s} u\right\|\right) .
\end{aligned}
$$


Consequently, we have

$$
\left\|x_{n+1}-Q_{s} u\right\|^{2} \leq\left(1-t_{n}\right)\left\|x_{n}-Q_{s} u\right\|^{2}+t_{n} \beta_{n}
$$

where

$$
\beta_{n}=2\left(1-t_{n}\right)\left\langle u-Q_{s} u, j\left(x_{n}-Q_{S} u\right)\right\rangle+c \frac{\rho_{E}\left(t_{n}\left\|u-Q_{S} u\right\|\right)}{t_{n}} .
$$

Since $E$ is a uniformly smooth Banach space, $\frac{\rho_{E}\left(t_{n}\left\|u-Q_{s} u\right\|\right)}{t_{n}} \rightarrow 0, \quad n \rightarrow \infty$. By (3.7), we obtain $\lim \sup _{n \rightarrow \infty} \beta_{n} \leq 0$. Hence, an application of Lemma 3.2 on (3.8) yields the desired result. $\square$

Now, we will give a method to solve more generally following problem:

Finding an element $x^{*} \in S=\cap_{i=1}^{N} \operatorname{Fix}\left(T_{i}\right)$,

where $T_{i}: C_{i} \rightarrow C_{i}, i=1,2, \ldots, N$ is a nonexpansive mapping and $C_{i}$ is a convex closed nonexpansive retract of $E$.

Obviously, we have the following lemma:

Lemma 3.5. Let $E$ be a Banach space, and let $C$ be a closed convex retract of $E$. Let $T$ $: C \rightarrow C$ be a nonexpansive mapping such that $\operatorname{Fix}(T) \neq \varnothing$. Then, Fix $(T)=\operatorname{Fix}\left(T Q_{C}\right)$, where $Q_{C}$ is a retraction of $E$ onto $C$.

We consider the iterative sequence $\left\{x_{n}\right\}$ defined by

$$
r_{n} \sum_{i=1}^{N} B_{i}\left(x_{n+1}\right)+x_{n+1}=t_{n} u+\left(1-t_{n}\right) x_{n}, u, x_{0} \in E, \quad n \geq 0,
$$

where $B_{i}=I-T_{i} Q_{C_{i}} i=1,2, \ldots, N$ and $Q_{C_{i}}$ is a nonexpansive retraction from $E$ onto $C_{i}, i=1,2, \ldots, N$.

Theorem 3.6. Suppose that $E$ is a uniformly convex and uniformly smooth Banach space which has a weakly sequentially continuous normalized duality mapping $j$ from $E$ into $E^{*}$. Let $C_{i}$ be a convex closed nonexpansive retract of $E$ and let $T_{i}: C_{i} \rightarrow C_{i}, i=1$, $2, \ldots, N$ be a nonexpansive mapping such that $S=\cap_{i=1}^{N} \operatorname{Fix}\left(T_{i}\right) \neq \emptyset$. If the sequences $\left\{r_{n}\right\}$ $\subset(0,+\infty)$ and $\left\{t_{n}\right\} \subset(0,1)$ satisfy

(i) $\lim _{n \rightarrow \infty} t_{n}=0 ; \sum_{n=0}^{\infty} t_{n}=+\infty$;

(ii) $\lim _{n \rightarrow \infty} r_{n}=+\infty$,

then the sequence $\left\{x_{n}\right\}$ generated by (3.10) converges strongly to $Q_{S} u$, where $Q_{S}$ is a sunny nonexpansive retraction from $E$ onto $S$.

Proof. By the Lemma 3.5, we have $S=\cap_{i=1}^{N} \operatorname{Fix}\left(T_{i} Q_{C_{i}}\right)$ and applying Theorem 3.4, we obtain the proof of this Theorem.

Next, we study the stability of the regularization algorithm (3.10) in the case that each $C_{i}$ is a closed convex sunny nonexpansive retract of $E$ with respect to perturbations of operators $T_{i}$ and constraints $C_{i}, i=1,2, \ldots, N$ satisfying following conditions:

(P1) Instead of $C_{i}$, there is a sequence of closed convex sunny nonexpansive retracts $C_{i}^{n} \subset E, n=1,2,3, \ldots$ such that

$$
\mathcal{H}\left(C_{i}^{n}, C_{i}\right) \leq \delta_{n}, \quad i=1,2, \ldots, N,
$$


where $\left\{\delta_{n}\right\}$ is a sequence of positive numbers.

(P2) For each set $C_{i}^{n}$, there is a nonexpansive self-mapping $T_{i}^{n}: C_{i}^{n} \rightarrow C_{i}^{n}, i=1,2, \ldots$, $N$ satisfying the conditions: if for all $t>0$, there exists the increasing positive functions $g(t)$ and $\xi(t)$ such that $g(0) \geq 0, \xi(0)=0$ and $x \in C_{i}, y \in C_{i}^{m},\|x-y\| \leq \delta$, then

$$
\left\|T_{i} x-T_{i}^{m} y\right\| \leq g(\max \{\|x\|,\|y\|\}) \xi(\delta) .
$$

We establish the convergence and stability of the regularization method (3.10) in the form:

$$
r_{n} \sum_{i=1}^{N} B_{i}^{n}\left(z_{n+1}\right)+z_{n+1}=t_{n} u+\left(1-t_{n}\right) z_{n}, u, z_{0} \in E, \quad n \geq 0,
$$

where $B_{i}^{n}=I-T_{i}^{n} Q_{C_{i}^{n}}, i=1,2, \ldots, N$ and $Q_{C_{i}^{n}}$ is a sunny nonexpansive retraction from $E$ onto $C_{i}^{n}, i=1,2, \ldots, N$.

Theorem 3.7. Suppose that $E$ is a uniformly convex and uniformly smooth Banach space which has a weakly sequentially continuous normalized duality mapping $j$ from $E$ into $E^{*}$. Let $C_{i}$ be a convex closed sunny nonexpansive retract of $E$ and let $T_{i}: C_{i} \rightarrow C_{i}$, $i=1,2, \ldots, N$ be nonexpansive mappings such that $S=\cap_{i=1}^{N} F i x\left(T_{i}\right) \neq \emptyset$. If the conditions (P1) and (P2) are fulfilled, and the sequences $\left\{r_{n}\right\},\left\{\delta_{n}\right\}$ and $\left\{t_{n}\right\}$ satisfy

(i) $\lim _{n \rightarrow \infty} t_{n}=0 ; \sum_{n=0}^{\infty} t_{n}=+\infty$;

(ii) $\lim _{n \rightarrow \infty} r_{n}=+\infty$;

(iii) $\sum_{n=0}^{\infty} r_{n} \xi\left(a \sqrt{h_{E}\left(\delta_{n}\right)}\right)<+\infty$ for each $a>0$,

then the sequence $\left\{z_{n}\right\}$ generated by (3.12) converges strongly to $Q_{S} u$, where $Q_{S}$ is a sunny nonexpansive retraction from $E$ onto $S$.

Proof. For each $n, \sum_{i=1}^{N} B_{i}^{n}$ is an $m$-accretive operator on $E$, so the equation (3.12) defines a unique element $z_{n+1} \in E$. From the equations (3.10) and (3.12), we have

$$
\begin{aligned}
& r_{n}\left\langle\sum_{i=1}^{N} B_{i}^{n}\left(z_{n+1}\right)-B_{i}^{n}\left(x_{n+1}\right), j\left(z_{n+1}-x_{n+1}\right)\right\rangle \\
& \quad+r_{n}\left\langle\sum_{i=1}^{N} B_{i}^{n}\left(x_{n+1}\right)-B_{i}\left(x_{n+1}\right), j\left(z_{n+1}-x_{n+1}\right)\right\rangle+\left\|z_{n+1}-x_{n+1}\right\|^{2} \\
& \quad=\left(1-t_{n}\right)\left\langle z_{n}-x_{n}, j\left(z_{n+1}-x_{n+1}\right)\right\rangle .
\end{aligned}
$$

By the accretivity of $\sum_{i=1}^{N} B_{i}^{n}$ and the equation (3.13), we deduce

$$
\left\|z_{n+1}-x_{n+1}\right\| \leq\left(1-t_{n}\right)\left\|z_{n}-x_{n}\right\|+r_{n} \sum_{i=1}^{N}\left\|B_{i}^{n}\left(x_{n+1}\right)-B_{i}\left(x_{n+1}\right)\right\| .
$$

For each $i \in\{1,2, \ldots, N\}$,

$$
\left\|B_{i}^{n}\left(x_{n+1}\right)-B_{i}\left(x_{n+1}\right)\right\|=\left\|T_{i}^{n} Q_{C_{i}^{n}} x_{n+1}-T_{i} Q_{C_{i}} x_{n+1}\right\| .
$$

Since $\left\{x_{n}\right\}$ is bounded and $\mathcal{H}\left(C_{i}, C_{i}^{n}\right) \leq \delta_{n}$, there exist constants $K_{1, i}>0$ and $K_{2, i}>1$ such that

$$
\left\|Q_{C_{i}^{n}} x_{n+1}-Q_{C_{i}} x_{n+1}\right\| \leq K_{1, i} \sqrt{h_{E}\left(K_{2, i} \delta_{n}\right)} \leq K_{1, i} \sqrt{K_{2, i} L} \sqrt{h_{E}\left(\delta_{n}\right)} .
$$


By the condition (P2),

$$
\left\|T_{i}^{n} Q_{C_{i}^{n}} x_{n+1}-T_{i} Q_{C_{i}} x_{n+1}\right\| \leq g\left(M_{i}\right) \xi\left(K_{1, i} \sqrt{K_{2, i} L} \sqrt{h_{E}\left(\delta_{n}\right)}\right),
$$

where $M_{i}=\max \left\{\sup \left\|Q_{C_{i}^{n}} x_{n+1}\right\|\right.$, sup $\left.\left\|Q_{C_{i}} x_{n+1}\right\|\right\}<+\infty$.

From (3.14), (3.15) and (3.17), we obtain

$$
\left\|z_{n+1}-x_{n+1}\right\| \leq\left(1-t_{n}\right)\left\|z_{n}-x_{n}\right\|+N g(M) r_{n} \xi\left(\gamma_{1,2} \sqrt{h_{E}\left(\delta_{n}\right)}\right),
$$

where $M=\max \left\{M_{1}, M_{2}, \ldots, M_{N}\right\}<+\infty$ and $\gamma_{1,2}=\max _{i=1,2, \ldots, N}\left\{K_{1, i} \sqrt{K_{2, i} L}\right\}$.

By the above assumption and Lemma 3.2, we conclude that ||$z_{n}-x_{n} \| \rightarrow 0$. In addition, by Theorem 3.6,

$$
\left\|z_{n}-Q_{s} u\right\| \leq\left\|z_{n}-x_{n}\right\|+\left\|x_{n}-Q_{s} u\right\| \rightarrow 0, \text { as } n \rightarrow \infty,
$$

which implies that $\left\{z_{n}\right\}$ converges strongly to $Q_{s} u$.

Finally, in this article we give a method to solve the following problem:

Finding an element $x^{*} \in S=\cap_{i=1}^{N} \operatorname{Fix}\left(T_{i}\right)$,

where $T_{i}: C_{i} \rightarrow E, i=1,2, \ldots, N$ is nonexpansive nonself-mapping and $C_{i}$ is a closed convex sunny nonexpansive retract of $E$.

Lemma 3.8. [14] Let $C$ be a closed convex subset of a strictly convex Banach space $E$ and let $T$ be a nonexpansive mapping from $C$ into $E$. Suppose that $C$ is a sunny nonexpansive retract of $E$. If $F i x(T) \neq \varnothing$, then $F i x(T)=F i x\left(Q_{C} T\right)$, where $Q_{C}$ is a sunny nonexpansive retraction from $E$ onto $C$.

We have the following result:

Theorem 3.9. Suppose that $E$ is a uniformly convex and uniformly smooth Banach space which has a weakly sequentially continuous normalized duality mapping $j$ from $E$ into $E^{*}$. Let $C_{i}$ be a convex closed sunny nonexpansive retract of $E$ and let $T_{i}: C_{i} \rightarrow E$, $i=1,2, \ldots, N$ be nonexpansive mappings such that $S=\cap_{i=1}^{N} F i x\left(T_{i}\right) \neq \emptyset$. If the sequences $\left\{r_{n}\right\} \subset(0,+\infty)$ and $\left\{t_{n}\right\} \subset(0,1)$ satisfy

(i) $\lim _{n \rightarrow \infty} t_{n}=0 ; \sum_{n=0}^{\infty} t_{n}=+\infty$;

(ii) $\lim _{n \rightarrow \infty} r_{n}=+\infty$,

then the sequence $\left\{u_{n}\right\}$ defined by

$$
r_{n} \sum_{i=1}^{N} f_{i}\left(u_{n+1}\right)+u_{n+1}=t_{n} u+\left(1-t_{n}\right) u_{n}, u, u_{0} \in E, \quad n \geq 0,
$$

converges strongly to $Q_{S} u$, where $Q_{S}$ is a sunny nonexpansive retraction from $E$ onto $S$ and $f_{i}=I-Q_{C_{i}} T_{i} Q_{C_{i}}, i=1,2, \ldots, \mathrm{N}$.

Proof. By the Lemma 3.5 and Lemma 3.8, $S=\cap_{i=1}^{N} \operatorname{Fix}\left(T_{i}\right)=\cap_{i=1}^{N} \operatorname{Fix}\left(f_{i}\right)$. Applying Theorem 3.4, we obtain the proof of this Theorem. 


\section{Author details}

${ }^{1}$ Department of Mathematics Education, Kyungnam University, Masan, Kyungnam, 631-701, Korea ${ }^{2}$ College of Sciences, Thainguyen University, Thainguyen, Vietnam

\section{Authors' contributions}

JKK conceived the study and participated in its design and coordination. JKK suggested many good ideas that are useful for achievement this paper and made the revision. TMT and JKK prepared the manuscript initially and performed all the steps of proof in this research. All authors read and approved the final manuscript.

\section{Competing interests}

The authors declare that they have no competing interests.

Received: 22 November 2010 Accepted: 16 September 2011 Published: 16 September 2011

\section{References}

1. Rockaffelar, RT: Monotone operators and proximal point algorithm. In J Control Optim, vol. 14, pp. 887-897.SIAM (1976)

2. Güler, O: On the convergence of the proximal point algorithm for convex minimization. In J Control Optim, vol. 29, pp. 403-419.SIAM (1991). doi:10.1137/0329022

3. Solodov, MV, Svaiter, BF: Forcing strong convergence of proximal point iteration in Hilert space. Math Program Ser A. 87, 189-202 (2000)

4. Kamimura, S, Takahashi, W: Strong convergence of a proximal-type algorithm in Banach spaces. In J Control Optim, vol. 13, pp. 938-945.SIAM (2002)

5. Lehdili, N, Moudafi, A: Combining the proximal algorithm and Tikhonov regularization. Optimization. 37, 239-252 (1996). doi:10.1080/02331939608844217

6. $\mathrm{Xu}, \mathrm{H}-\mathrm{K}:$ A regularization method for the proximal point algorithm. J Glob Optim. 36, 115-125 (2006). doi:10.1007/ s10898-006-9002-7

7. Song, Y, Yang, C: A note on a paper: a regularization method for the proximal point algorithm. J Glob Optim. 43, 171-174 (2009). doi:10.1007/s10898-008-9279-9

8. Figiel, T: On the moduli of convexity and smoothness. Stud Math. 56, 121-155 (1976)

9. Alber, Y: On the stability of iterative approximations to fixed points of nonexpansive mappings. J Math Anal Appl. 328, 958-971 (2007). doi:10.1016/j.jmaa.2006.05.063

10. Alber, Y, Ryazantseva, I: Nonlinear III-Posed Problems of Monotone Type. Dordrecht: Springer (2006)

11. Li, G, Kim, JK: Demiclosed principle and asymptotic behavior for nonexpansive mappings in metric spaces. Appl Math Lett. 14, 645-649 (2001). doi:10.1016/S0893-9659(00)00207-X

12. Reich, S: Strong convergence theorems for resolvents of accretive operators in Banach space. J Math Anal Appl. 75 , 287-292 (1980). doi:10.1016/0022-247X(80)90323-6

13. $\mathrm{Xu}, \mathrm{H}-\mathrm{K}$ : Strong convergence of an iterative method for nonexpansive and accretive operators. J Math Anal Appl. 314 , 631-643 (2006). doi:10.1016/j.jmaa.2005.04.082

14. Matsushita, S, Takahashi, W: Strong convergence theorem for nonexpansive nonself-mappings without boundary conditions. Nonlinear Anal TMA. 68, 412-419 (2008). doi:10.1016/j.na.2006.11.007

doi:10.1186/1687-1812-2011-52

Cite this article as: Kim and Tuyen: Regularization proximal point algorithm for finding a common fixed point of a finite family of nonexpansive mappings in Banach spaces. Fixed Point Theory and Applications 2011 2011:52.

\section{Submit your manuscript to a SpringerOpen ${ }^{\ominus}$ journal and benefit from:}

- Convenient online submission

- Rigorous peer review

- Immediate publication on acceptance

- Open access: articles freely available online

- High visibility within the field

- Retaining the copyright to your article

Submit your next manuscript at $\boldsymbol{s p r i n g e r o p e n . c o m ~}$ 